\title{
The $\kappa \mathrm{B}$ Enhancer Motifs in Human Immunodeficiency Virus Type 1 and Simian Virus 40 Recognize Different Binding Activities in Human Jurkat and H9 T Cells: Evidence for NF- $\kappa B$-Independent Activation of the $\kappa B$ Motif
}

\author{
WILLIAM PHARES, $\dagger$ B. ROBERT FRANZA, JR., AND WINSHIP HERR* \\ Cold Spring Harbor Laboratory, Cold Spring Harbor, New York 11724
}

Received 9 July 1992/Accepted 15 September 1992

\begin{abstract}
The $\mathrm{kB}$ transcriptional enhancer motif, present in many viruses, is broadly active in many cell types. It is recognized by c-Rel/HIVEN86A in DNA affinity precipitation (DNAP) assays and by the Rel-related p50 and p65 subunits of the nuclear factor NF-kB in electrophoretic mobility shift assays (EMSA). We have analyzed activities that bind the human immunodeficiency virus type 1 and simian virus $\mathbf{4 0} \mathrm{kB}$ motifs in two human leukemia cell lines, Jurkat and H9. In both DNAP and EMSA analyses of Jurkat cell extracts, we detected multiple $\kappa B$ motif-binding activities in addition to c-Rel/HIVEN86A and p50-p65 NF-kB. In Jurkat cell nuclear extracts, EMSA analysis revealed at least six specific DNA-protein complexes, of which one comigrated with the p50-p65 NF-kB complex. Formation of all six complexes was enhanced by stimulation of the cells with phorbol 12-myristate-13-acetate and phytohemagglutinin but was differentially affected by the salt concentration in the binding reaction and by the conditions of Jurkat cell growth. Nuclear extracts from both unstimulated and stimulated $\mathrm{H} 9$ cells revealed similar levels of five $\mathrm{\kappa B}$ motif-specific complexes, all of which displayed mobilities distinct from those of the Jurkat cell complexes. Indeed, a complex corresponding to p50-p65 NF-kB was not detectable in nuclear extracts from unstimulated $\mathrm{H} 9$ cells although such a complex was apparent in nuclear extracts from stimulated $\mathrm{H} 9$ cells. In contrast to the inducibility of a p50-p65 NF-kB-like complex, transcriptional enhancers composed of multimerized $\kappa B$ motifs displayed similar high levels of activity in both the unstimulated and stimulated $\mathrm{H} 9$ cells. Thus, the activity of the $\mathrm{\kappa B}$ motif in $\mathrm{H9}$ cells corresponded to the abundance of the $H 9$ cell-specific $\kappa B$ motif complexes and not to the levels of p50-p65 NF- $\kappa B$ complex. These results suggest that the broad activity of the $\mathrm{kB}$ enhancer element is not only due to the broadly distributed $\mathrm{NF}-\kappa \mathrm{B}$ activator but also to cell type-specific $\kappa \mathrm{B}$ motif-binding activities.
\end{abstract}

The cell-specific activity of viral and cellular promoters results from the concerted interaction of a number of promoter elements (16). One such element is the $\mathrm{\kappa B}$ motif, which was originally identified as a binding site for the nuclear factor NF- $\mathrm{kB}$ within the $\kappa$ immunoglobulin lightchain enhancer (44). This element, which contains the conserved 10-bp sequence motif GGGACTTTCC (reviewed in reference 1), has been found in both cell-specific and generally active viral and cellular enhancers and is active in many cell types following cellular stimulation with different agents (reviewed in reference 27). This motif or proto-enhancer is also active in many uninduced cell types in culture upon multimerization $(23,35,37,42)$.

The best-characterized cellular factors that recognize the $\kappa \mathrm{B}$ motif are c-Rel/HIVEN86A in DNA affinity precipitation (DNAP) assays $(19,26)$ and NF- $\mathrm{KB}$ in electrophoretic mobility shift assays (EMSA) (44); NF- $\mathrm{BB}$ is a heterodimeric complex composed of 50- (p50) and 65-kDa (p65) polypeptides (48). These three proteins all contain large regions of similarity called the Rel domain $(10,12,20,25,31,34,40$, 50 , which are sufficient for dimerization and DNA binding (reviewed in references 1 and 21). In HeLa cells, NF- $k B$ is sequestered in the cytoplasm as an inactive complex with the inhibitor IKB $(2,3)$. Upon cellular stimulation, the p50-p65 $\mathrm{NF}-\kappa \mathrm{B}$ complex dissociates from I $\mathrm{KB}$ and appears in the

\footnotetext{
* Corresponding author.

† Present address: Sandoz Research Institute, Brunnerstrasse 59, A-1235 Vienna, Austria.
}

nucleus as an active $\kappa B$ motif-binding complex (45). The inactive I $\mathrm{kB}$-associated form of NF-kB can be activated in vitro by mild denaturation, which artificially dissociates I $\mathbf{B}$ from NF-kB (2). The DNA-binding activity of c-Rel can also be modulated in a similar fashion by association with pp40 (14).

In addition to c-Rel, high-resolution, two-dimensional electrophoretic analysis of $\mathbf{k B}$ motif-binding proteins obtained by DNAP reveals other proteins that recognize $\kappa B$ motifs $(6,8,18,19)$. The identity of most of these proteins is not known, but subsets of the $\mathrm{kB}$-binding proteins in Jurkat and $\mathrm{H} 9$ cells are unique to each cell type (19). By EMSA analysis, the p50 subunit and to a much lesser extent the p65 subunit of NF-kB are able to form unique complexes by binding to $\mathrm{\kappa B}$ motifs as homodimers (48). Characterization of molecularly cloned cDNAs has also revealed human and murine proteins related to the $\mathrm{p} 50$ and $\mathrm{p} 65 \mathrm{NF}-\mathrm{kB}$ proteins referred to as p49 (43) or p50B (9) and RelB (41), respectively. In a transient expression assay, these proteins can activate transcription through the $\kappa \mathrm{B}$ motif, but they have not been identified as $\mathbf{k B}$ motif-binding proteins in cellular extracts $(9,41,43)$.

We have previously compared the activities of $\mathbf{k B}$ motifs found within the enhancers of the simian DNA virus simian virus 40 (SV40) and the human immunodeficiency virus type 1 (HIV-1). It had been suggested that the previously described broad activity of the SV40 enhancer $\mathrm{kB}$ motif might be due to broadly active overlapping cis-regulatory elements not found associated with other $\mathrm{kB}$ elements (38). We found, 
however, by two different tests that the activities of the SV40 $\kappa B$ motif and the two HIV-1 $\mathrm{\kappa B}$ motifs are very similar even though they are embedded in different flanking sequences (37). The HIV-1 kB sites can replace the SV40 enhancer to support SV40 growth in African green monkey kidney cells, and multimerized copies of each of the three individual motifs display similar activities in a variety of cell lines. To extend this prior study, we investigated the nature of SV40 and HIV-1 $\mathrm{kB}$ motif-binding proteins in a variety of cell lines. Unexpectedly, we found the patterns of $\mathrm{kB}$ motif-binding proteins displayed by DNAP and EMSA analysis to be remarkably complex and to differ greatly in extracts from Jurkat and H9 cells, two human T-cell lines. Indeed, although unstimulated $\mathrm{H} 9$ cell nuclear extracts display many $\mathbf{\kappa B}$ motif-binding activities, they display very little, if any, p50-p65 NF- $\mathrm{kB}$ complex. Even in the absence of evident NF- $\mathrm{kB}$ activator, however, the $\mathbf{k B}$ motif is nevertheless very active in these cells, suggesting that other cell-specific $\mathrm{kB}$ motif-binding complexes can activate transcription in addition to NF- $\mathrm{kB}$.

\section{MATERIALS AND METHODS}

Cell culture. H9 cells (derived from HuT78) (39) were grown in RPMI 1640 medium supplemented with $10 \%$ fetal bovine serum-2 $\mathrm{mM}$ glutamine-20 mM N-2-hydroxyethylpiperazine- $N^{\prime}$-2-ethanesulfonic acid (HEPES; pH 7.3)antibiotics. Cultures were maintained in a state of continuous growth at cell densities between $1 \times 10^{5} / \mathrm{ml}$ and $1 \times 10^{6}$ to $2 \times 10^{6} / \mathrm{ml}$ by splitting them $1: 15$ every 4 days in $15 \mathrm{ml}$ of medium in 100-mm-diameter dishes. Two cultures of Jurkat cells (49), Jk-1 and Jk-2, were grown separately. Except where noted, Jk-1 cells were used for all of the EMSA experiments. Jk-1 was grown exactly as described above for H9 cells. Jk-2 cultures were used for the DNAP analysis and were grown in RPMI 1640 medium supplemented only with $15 \%$ fetal bovine serum in T-150 flasks lying on their sides. The Jk-2 cell densities were maintained between $2 \times 10^{5}$ and $8 \times 10^{5} / \mathrm{ml}$ in 100 to $150 \mathrm{ml}$ of medium. All cultures were grown at $37^{\circ} \mathrm{C}$ in an atmosphere of $5 \% \mathrm{CO}_{2}$ in humidified incubators.

Microscale DNAP and high-resolution, two-dimensional electrophoresis. DNA probes for affinity precipitation were prepared from gel-purified synthetic oligonucleotides. Complementary oligonucleotides, each at $1 \mu \mathrm{g} / \mu \mathrm{l}$, were mixed in $10 \mathrm{mM}$ Tris- $\mathrm{HCl}(\mathrm{pH} 7.8)-5 \mathrm{mM} \mathrm{MgCl}$; the solution was heated at $70^{\circ} \mathrm{C}$ for $10 \mathrm{~min}$ and then allowed to cool to room temperature. The double-stranded oligonucleotides were end phosphorylated with polynucleotide kinase and ligated overnight at $16^{\circ} \mathrm{C}$ with T4 DNA ligase. Biotinylation of the DNA probes, preparation of whole-cell extracts from Jurkat cells, binding reactions, and high-resolution, two-dimensional electrophoresis were performed as described previously (19). Jurkat cells were treated with phorbol 12-myristate-13-acetate (PMA) and phytohemagglutinin (PHA) for $3.5 \mathrm{~h}$ prior to a 30 -min labeling in methionine-free Dulbecco modified Eagle medium containing $1 \mathrm{mCi}$ of $\mathrm{L}-\left[{ }^{35} \mathrm{~S}\right]$ methionine per $\mathrm{ml}$.

EMSA. Nuclear extracts of Jurkat or $\mathrm{H} 9$ cells were prepared as described previously (15); after dialysis against buffer D, 1\% Nonidet P-40 (NP-40) was added (2) and the extracts were quickly frozen in liquid nitrogen and stored at $-70^{\circ} \mathrm{C}$. Phenylmethylsulfonyl fluoride and dithiothreitol were added to buffers just before use. Stimulation of cultures with PHA $(1 \mu \mathrm{g} / \mathrm{ml})$ and PMA $(10 \mathrm{nM})$ was for $8 \mathrm{~h}$. The protein concentration of cell extracts was estimated by dye binding (11) with commercial reagents (BioRad) and bovine serum gamma globulin as the standard. DNA probes were prepared by polymerase chain reaction amplification, using 5 '-32 P-end-labeled universal pUC forward and reverse oligonucleotide primers. Single-stranded DNA templates for the amplification reaction were phagemid DNAs containing a single $\kappa \mathrm{B}$ sequence (Fig. 1) within the pUC119 polylinker; the $\kappa B$ sequences were obtained by $X h o I$ digestion of the six-time-multimerized $\mathbf{\kappa B}$ enhancers previously described (37), followed by filling in of the ends and insertion of a single copy into the SmaI site of pUC119, such that in the orientation shown in Fig. 1 the pUC119 EcoRI site lies $3^{\prime}$ of the $\mathrm{\kappa B}$ insert. Probes were purified on $5 \%$ native polyacrylamide gels, eluted in $10 \mathrm{mM}$ Tris- $\mathrm{HCl}(\mathrm{pH} \mathrm{7.8)}-50 \mathrm{mM} \mathrm{NaCl}-0.1$ mM EDTA overnight at $4^{\circ} \mathrm{C}$, and stored frozen at $-20^{\circ} \mathrm{C}$.

Conditions for binding reactions (except where noted) were adapted from published procedures (44). For each reaction, $5 \mu \mathrm{g}$ of protein was diluted to $2 \mu \mathrm{l}$ in buffer D (15) containing $0.5 \%$ NP- 40 , mixed at room temperature with $7 \mu \mathrm{l}$ of $1.4 \times$ binding mixture and subsequently $1 \mu$ of probe $\left(10,000\right.$ to $20,000 \mathrm{cpm} ; 10^{-15} \mathrm{~mol}$ probe), and incubated at room temperature for $30 \mathrm{~min}$ prior to polyacrylamide gel electrophoresis. The final composition of the $10-\mu l$ binding reaction mixture was (including salt from extract and probe) $10 \mathrm{mM}$ Tris- $\mathrm{HCl}$ (pH 7.5), $55 \mathrm{mM} \mathrm{NaCl}, 20 \mathrm{mM} \mathrm{KCl}, 1 \mathrm{mM}$ dithiothreitol, 1 mM EDTA, 5\% glycerol, 2\% Ficoll-400, $0.2 \% \mathrm{NP}-40,0.1 \mu \mathrm{g}$ of denatured fish sperm DNA, and $1 \mu \mathrm{g}$ of poly(dI-dC)-poly(dI-dC) except for the experiment in Fig. $5 \mathrm{~A}$ in which there was $10 \mathrm{mM} \mathrm{KCl}, 3 \%$ glycerol, $0.1 \%$ $\mathrm{NP}-40$, and $\mathrm{NaCl}$ as indicated in the figure. To denature extracts mildly (2), the following were sequentially added to $2 \mu \mathrm{l}$ of diluted extract (as above) with gentle mixing following each addition: $0.75 \mu$ l of deionized formamide, $5.25 \mu \mathrm{l}$ of $1.9 \times$ binding mixture, $1 \mu \mathrm{l}$ of probe, and $1 \mu \mathrm{l}$ of $2 \%$ sodium deoxycholate; subsequent incubation was at room temperature for $30 \mathrm{~min}$. Electrophoresis was at room temperature through a 5\% native polyacrylamide gel (acrylamide-bisacrylamide, 29:1, deionized) containing $20 \mathrm{mM}$ Tris base and 0.2 $M$ glycine; the gel was pre-run at $11 \mathrm{~V} / \mathrm{cm}$ for $30 \mathrm{~min}$, and electrophoresis of samples was at the same voltage for approximately $2 \mathrm{~h}$. The gels were fixed in 10\% acetic acid-10\% methanol, dried, and subjected to autoradiography at $-70^{\circ} \mathrm{C}$ with an intensifying screen.

Activity assays of multimerized synthetic $\kappa B$ proto-enhancers. H9 cells, with and without stimulation with PMA and PHA, were transfected by electroporation with human $\beta$-globin expression vectors containing six tandem copies of synthetic proto-enhancers cloned into the SphI site downstream of the $\beta$-globin sequences, as described previously (37). Purified plasmid DNAs were transfected along with a human $\alpha$-globin plasmid (pBS $\alpha 2)$ as an internal control. Isolation of RNA and RNase protection of $\alpha$ - and $\beta$-globin antisense probes were performed as described previously (22). The bands corresponding to correctly initiated $\alpha$ - and $\beta$-globin RNAs were quantitated by liquid scintillation spectrometry. Quantitation was normalized to the internal control and is expressed relative to the activity of the $\beta$-globin vector containing a single copy of a nonduplicated form of the SV40 enhancer $(1 \times 72)$ as described previously (37).

\section{RESULTS}

Figure 1 shows the sequences of the three wild-type and three mutant probes used here to characterize $\mathrm{kB}$ motifbinding proteins in Jurkat and $\mathrm{H} 9 \mathrm{~T}$ cells. These six sequences are identical to those which were previously multi- 


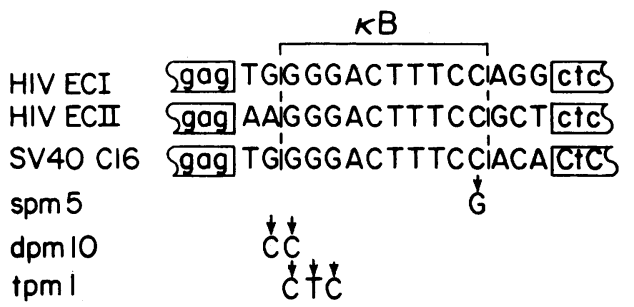

FIG. 1. Sequences of $\kappa B$ oligonucleotides used to prepare singlesite probes. ECI and ECII are the downstream and upstream HIV-1 enhancer core elements, respectively; $\mathrm{Cl6}$ is derived from the $\mathrm{C}$ proto-enhancer element of SV40. The mutant $s p m 5, d p m 10$, and tpm 1 sites, in which the individual point mutations are indicated by arrows below the $\mathrm{C} 16$ sequence, are derived from the $\mathrm{C} 16$ sequence. Each of the wild-type oligonucleotides contains the conserved 10-bp $\kappa \mathrm{B}$ motif (bracketed by the broken lines) surrounded by the individual flanking bases found in each site. The outermost boxed 3-bp sequences shown are derived from XhoI linker sequences.

merized to create synthetic $\kappa B$ enhancers (37). In each of the wild-type sites, one from the SV40 enhancer (C16) and two from the HIV-1 enhancer (ECI and ECII), the 10-bp $\kappa B$ sequence is flanked by at least the two $5^{\prime}$ and three $3^{\prime}$ base pairs (as shown in the figure) that normally flank the corresponding wild-type site; the remaining sequences shown represent $X h o I$ linker sequences. The three mutant sites are related to the SV40 C16 site and contain one (spm5), two $(d p m 10)$, or three $(t p m 1)$ point mutations. Each of these mutations debilitates $\mathbf{\kappa B}$ motif function in induced and uninduced cells except for that of the $d p m 10$ mutant which is very active in induced Jurkat cells (37).

Three distinct $\kappa B$ motifs display similar complex proteinbinding patterns by either DNAP or EMSA. We assayed $\kappa B$ motif-binding proteins in Jurkat cell extracts by both DNAP and EMSA analysis. Figure 2 shows the results of highresolution, two-dimensional gel electrophoresis of DNA affinity precipitates with the radiolabeled Jurkat whole-cell extracts and binding sites shown in Fig. 1. Previous work using probes containing the $\kappa B$ site from the interleukin-2 receptor $\alpha$ promoter or both HIV-1 enhancer $\mathbf{k B}$ sites revealed a complex pattern of $\kappa B$-binding proteins $(6,8,18$, 19). To compare by DNAP assay the multimerized sites characterized previously in transcriptional assays (37), probes were prepared by ligation of paired oligonucleotides containing the individual sites. As shown in each of the panels in Fig. 2, irrespective of the binding site used, a variety of nonspecific proteins are recovered in the DNAP assays, including the heat shock proteins HSP73 and HSP90, tubulin, and actin (panel A); these proteins serve as mobility markers. Each of the wild-type SV40 and HIV-1 $\kappa B$ sites (panels B, C, and D) bound a large number of additional radiolabeled proteins in extracts from PMA- and PHAstimulated Jurkat cells that were not recovered with the tpm 1 mutant site (panel E) or with the wild-type ECI probe from unstimulated Jurkat cell extracts (panel A). These additional proteins included c-Rel/HIVEN86A $(19,26)$ and seven sets of proteins labeled A through G. The protein labeled $\mathrm{C}$, which was not efficiently recovered with the ECI probe (compare panel $B$ with panels $C$ and $D$ ), is the only protein not to appear with all three wild-type probes. These results show that there are a large variety of proteins that recognize all three of these different $\kappa B$ motifs in a DNAP assay. Because when the sequences of all three wild-type sites are compared (Fig. 1) there are no flanking residues shared by all three sites, these results suggest that the $\kappa \mathrm{B}$ motif per se can recognize a large number of Jurkat cell proteins, although slight variations in the patterns may be due to the flanking sequences.

Figure 3 shows the result of an EMSA with the six different $\kappa B$-related sites shown in Fig. 1 and nuclear extracts prepared from either unstimulated Jurkat cells (lanes 1 to 6) or Jurkat cells stimulated with PMA and PHA under conditions identical to those used in the enhancer assays described previously (37) (lanes 7 to 12). By analyzing nuclear extracts, we can compare the binding activity of nuclear factors with the transcriptional activity of the enhancer. Consistent with their transcriptional activity, nuclear factor binding to the three wild-type sites is much greater in extracts from induced as opposed to uninduced cells (compare lanes 7 to 9 with lanes 1 to 3 ; lanes $7^{\prime}$ to $9^{\prime}$ represent a shorter exposure of the induced samples). The EMSA pattern, however, is more complex than that previously reported with Jurkat cell extracts $(4,8,19,28,29,32$, $33,47)$.

We detected at least six different inducible complexes (labeled 1 through 6), which we refer to as complexes J1 through J6. The sequence specificity of all six complexes is evidenced by the lack of complex formation with the mutant spm 5 and tpm 1 mutant sites (compare lanes 7 to 9 with lanes 10 and 12). One complex that migrates slightly faster than complex $\mathrm{J} 6$ and that is not affected by stimulation of the cells is apparently nonspecific, since the mutations have no effect on formation of this complex. In the extract from uninduced cells, complexes $\mathrm{J} 3$ to $\mathrm{J} 5$, but not $\mathrm{J} 1, \mathrm{~J} 2$, and $\mathrm{J} 6$, are evident with the wild-type probes, in particular with the ECII probe (lane 2). In the induced cell extract, the $d p m 10 \mathrm{kB}$ mutant site, but not the spm5 and tpm 1 mutant sites, is able to form complexes $\mathrm{J} 3$ and $\mathrm{J} 4$. This binding activity is consistent with the ability of the $d p m 10$ site to activate transcription in stimulated Jurkat cells, but the relatively low dpm 10 binding activity does not correlate with its relative level of transcriptional activity because the multimerized $d p m 10 \mathrm{kB}$ enhancer displays about $50 \%$ of the level of the wild-type sites in induced Jurkat cells (37). We do not know at present the reason for this apparent discrepancy.

To identify which of the multiple Jurkat $\kappa B$ EMSA complexes might correspond to an NF-kB complex, we compared their mobilities with that of a bona fide NF-kB complex obtained by mild denaturation of a HeLa cytoplasmic extract with formamide and deoxycholate (2). Figure 4 shows the results of such an experiment. The untreated HeLa cell cytoplasmic extract (lane 1) generates a complex that does not correspond to any of the Jurkat cell complexes (lane 4). We do not know the identity of this complex. Treatment of the HeLa cytoplasmic extract with formamide and deoxycholate, however, results in the formation of a prominent $\mathrm{kB}$-specific NF- $\mathrm{kB}$ complex (compare lanes 2 and 3 ). This complex comigrates with the Jurkat cell complex J3, suggesting that complex J3 corresponds to the p50-p65 NF-KB complex.

Salt concentration and cell growth afiect the Jurkat cell EMSA pattern. The pattern of complexes obtained with Jurkat cell extracts shown in Fig. 3 and 4 is more complicated than previously described $(4,8,19,28,29,32,33,47)$. We have found that the concentration of salt in the binding reaction and the conditions of Jurkat cell culture can influence the EMSA pattern. These two different effects are illustrated in Fig. 5. The effect of two different salt concentrations is shown in Fig. 5A. Each sample contained $10 \mathrm{mM}$ $\mathrm{KCl}$. The samples labelled $80 \mathrm{mM}$ (lanes 1 and 2) also 

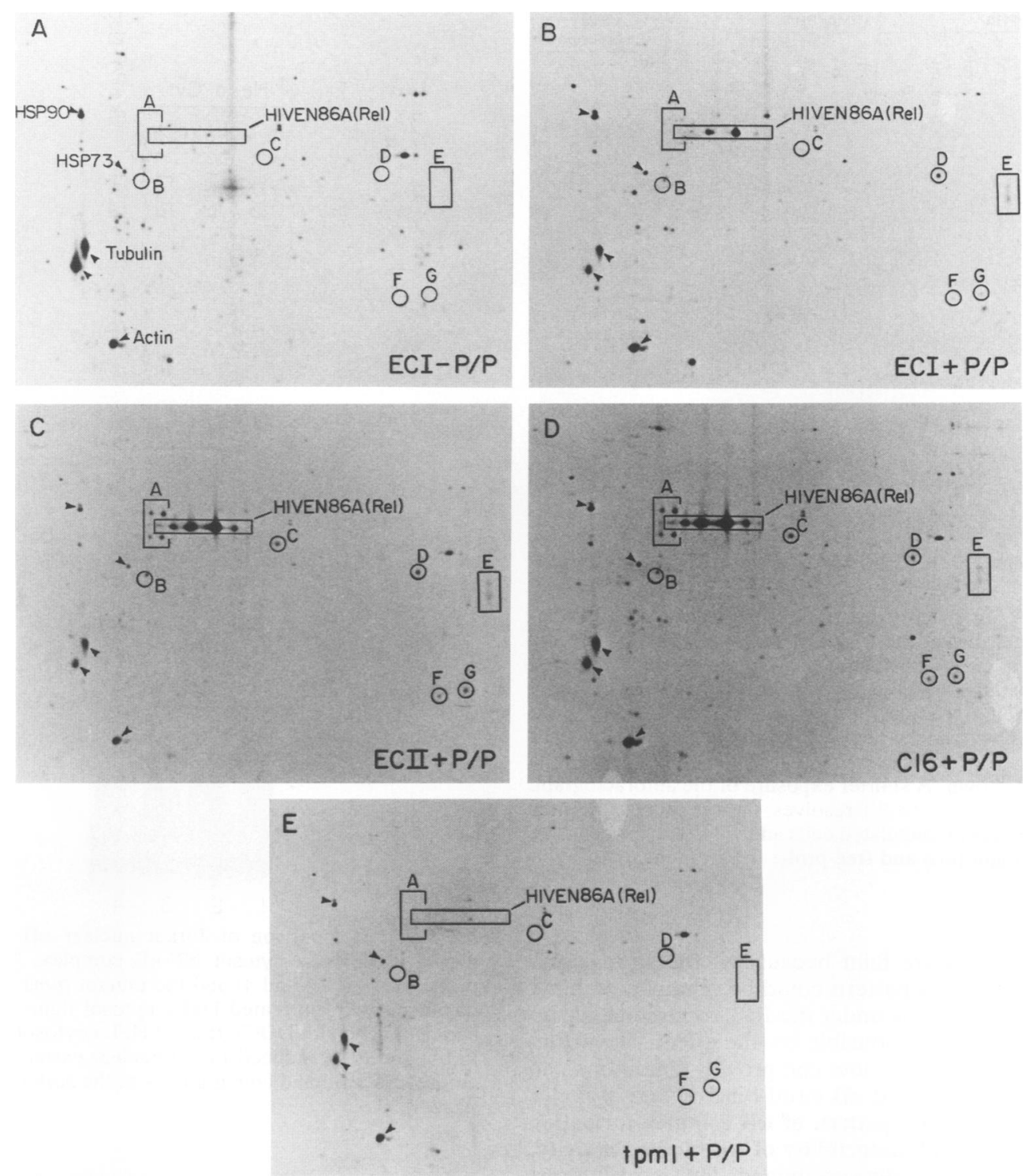

FIG. 2. Relative binding of constitutive and PMA- and PHA-inducible Jurkat proteins to wild-type and mutant $\mathrm{kB}$ motif-containing probes by DNAP and high-resolution, two-dimensional electrophoresis. DNAP proteins were resolved on a broad-range isoelectric focusing gel (using LKB ampholytes 3.5 to 10.0) and a second-dimension $10 \%$ polyacrylamide-sodium dodecyl sulfate gel. The portion of the gel image shown extends from isoelectric points of 4.5 to 7.5 (acidic proteins oriented to the left), with apparent molecular sizes of 40 to $150 \mathrm{kDa}$ (apparent molecular size decreasing from top to bottom). Shown are the patterns obtained from unstimulated Jurkat cell extracts precipitated by the ECI probe (A) and from PMA- and PHA-stimulated cell extracts precipitated by ECI (B), ECII (C), C16 (D), and by the mutant tpm1 probe (E). Spots corresponding to $\mathrm{KB}$ motif-binding proteins are boxed. Some nonspecifically precipitated proteins which serve as markers are indicated by arrows and are identified in panel $A$.

contained $70 \mathrm{mM} \mathrm{NaCl}$, whereas the samples labeled $40 \mathrm{mM}$ (lanes 3 and 4) only contained $30 \mathrm{mM} \mathrm{NaCl}$. The changes in salt concentration did not obviously affect the sequence specificity of complex formation (compare lanes 1 and 3 with lanes 2 and 4). Formation of complexes $\mathrm{J} 3$ to $\mathrm{J} 6$ was favored by the high salt concentration, whereas complexes $\mathrm{J} 1$ (visible on longer exposure of the autoradiograph) and $\mathrm{J} 2$ were favored by the lower salt concentration (compare lanes 1 and 3 ). Curiously, the mobility of complex J2 was also slightly retarded under the conditions of lower salt concentration. These results show that the binding conditions can influence the relative abundance of the Jurkat cell $\mathrm{\kappa B}$ motif complexes.
Figure 5B shows a comparison of the EMSA patterns generated by nuclear extracts from two sets of Jurkat cells, Jk-1 and Jk-2. Jk-1 cultures were obtained by propagation of Jk-2 cells under the conditions described in Materials and Methods. Like the Jk-1 cell extracts used in the aforementioned experiments, a nuclear extract from the uninduced Jk-2 cells displays little $\mathbf{k B}$ motif-binding activity (Fig. 5B, lanes 3 and 4). $\mathrm{kB}$ motif-specific complexes are induced, however, by stimulation of the Jk- 2 cells with PMA and PHA (lanes 5 and 6), but the pattern differs from that observed with the stimulated Jk-1 cell extract (lanes 1 and 2). In the Jk-2 extract, the NF-kB-like complex (J3) predominates, whereas the levels of complexes $\mathrm{J} 4$ to $\mathrm{J} 6$ are reduced 


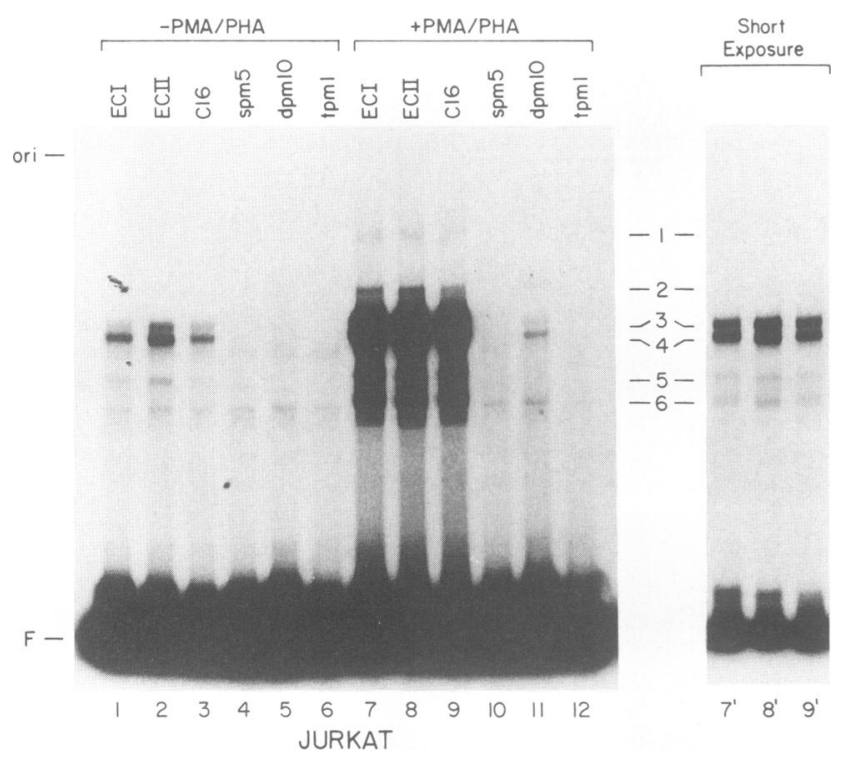

FIG. 3. EMSA of nuclear extracts from unstimulated and PMAand PHA-stimulated Jurkat cells reveal at least six $\mathbf{\kappa B}$ motif-specific DNA-protein complexes. The positions of the complexes, numbered 1 through 6 , are indicated to the right of the main panel. The probe used in each binding reaction is given at the top of each lane. Complexes formed with nuclear extracts of unstimulated cells (lanes 1 to 6) or with nuclear extracts of PMA- and PHA-stimulated cells (lanes 7 to 12) are shown. A shorter exposure of the autoradiograph for lanes 7 to 9 (lanes $7^{\prime}$ to $9^{\prime}$ ) resolves the overexposed bands obtained with extracts of stimulated cells and wild-type probes. The positions of the origin (ori) and free probe (F) are indicated.

(complexes $\mathrm{J} 5$ and $\mathrm{J} 6$ are faint because of the short exposure). Although the Jk-1 pattern could be obtained within 1 week of culturing Jk- 2 cells under the Jk-1 conditions, we do not know the factor(s) responsible for the effect. Nevertheless, these results illustrate how cell growth conditions can alter the patterns of induced $\kappa \mathrm{B}$ motif-binding activity.

$H 9$ cells show a distinct pattern of $\kappa B$ complex formation and little PMA and PHA inducibility of $\kappa B$-binding activity. The second human T-cell line examined, $\mathrm{H} 9$, is of interest because it supports high levels of replication of laboratory HIV-1 strains (39). In this cell line, the wild-type SV40 and HIV-1 $\kappa B$ motifs are active in unstimulated cells $(24,37)$ and several $\kappa \mathrm{B}$ motif-binding proteins identified by DNAP are unique to this cell line (19).

Figure 6 shows a comparison of Jurkat and H9 cell nuclear extracts from unstimulated cells or cells stimulated with PMA and PHA. Each of the four resulting extracts was also treated with formamide and deoxycholate to determine the susceptibility of the various complexes to mild denaturation and to reveal any sequestered NF- $\mathrm{KB}$ activity in the nuclear extracts. Unlike Jurkat cells in which there is little $\kappa B$ motif-binding activity in the absence of treatment with PMA and PHA (compare lanes 1 and 3 ), uninduced $\mathrm{H} 9$ cells already display five $\mathrm{\kappa B}$ motif-binding activities in unstimulated cell extracts (lane 5, complexes $\mathrm{H} 1, \mathrm{H} 2, \mathrm{H} 4, \mathrm{H} 6$, and $\mathrm{H7}$ ) and there is only a small general increase in formation of these complexes with the stimulated cell extracts (lane 7). As in the case of the Jk-1 Jurkat cell EMSA patterns, this H9 EMSA pattern is also more complex than previously reported $(3,19)$. The $\kappa B$ motif specificity of the complexes formed with the H9 cell nuclear extracts was established as

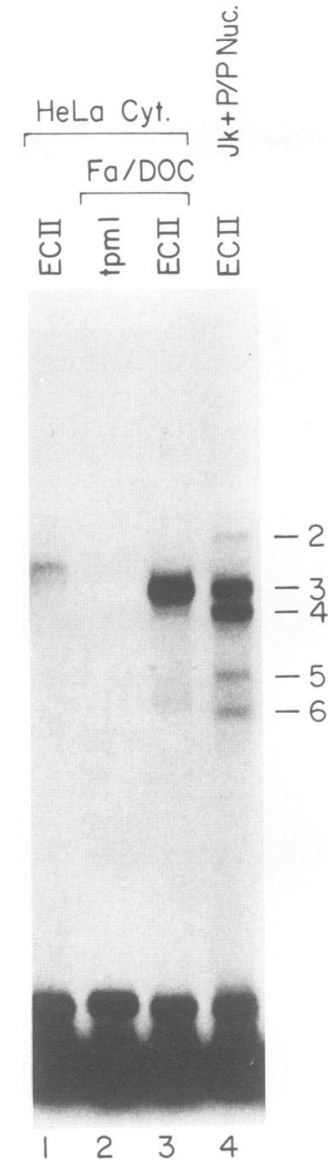

FIG. 4. Comparison of Jurkat nuclear $\mathrm{kB}$ motif-binding complexes with HeLa cytosol NF-kB complex. The wild-type ECII probe (lanes 1,3 , and 4 ) and the mutant tpm 1 probe (lane 2) were combined with untreated HeLa cytosol (lane 1), formamide ( $\mathrm{Fa}$ )and deoxycholate (DOC)- treated HeLa cytosol (lanes 2 and 3), or a PMA- and PHA-induced Jurkat nuclear extract (lane 4). The HeLa cytosol NF-kB band comigrates with the Jurkat nuclear complex J3 (lane 4).

shown in Fig. 6B, in which all of the complexes can also form with the SV40 C16 $\mathrm{kB}$ motif (compare lanes 1 and 2) but not with the single SV40 kB point mutant spm5 (lane 3). None of the five complexes produced by the unstimulated H9 nuclear extract complexes, however, comigrated with any of the six complexes formed with stimulated Jurkat cell extracts (compare lanes 5 and 3 in Fig. 6A). Indeed, no NF-kB-like complex was evident with the unstimulated H9 cell extract (lane 5), although upon stimulation with PMA and PHA formation of an NF- $\mathrm{BB}$-like complex was induced (complex H5 in lane 7) together with a weak complex labeled H3 (Fig. 6B, lane 1). Even after stimulation, however, the $\mathrm{NF}-\mathrm{\kappa B}$ complex still represents only a minor proportion of the total $\mathrm{\kappa B}$ motif-binding activity present in an $\mathrm{H} 9$ nuclear extract.

Treatment of the Jurkat and $\mathrm{H} 9$ nuclear extracts with formamide and deoxycholate (even-numbered lanes in Fig. $6 \mathrm{~A})$ revealed a differential susceptibility of the Jurkat and $\mathrm{H} 9$ complexes to mild denaturation. In all of the extracts, the NF-kB-like complex was induced by the denaturation protocol. This induction may reflect some NF- $\mathrm{KB}$ activity sequestered by IkB, possibly due to cytoplasmic contamina- 
A

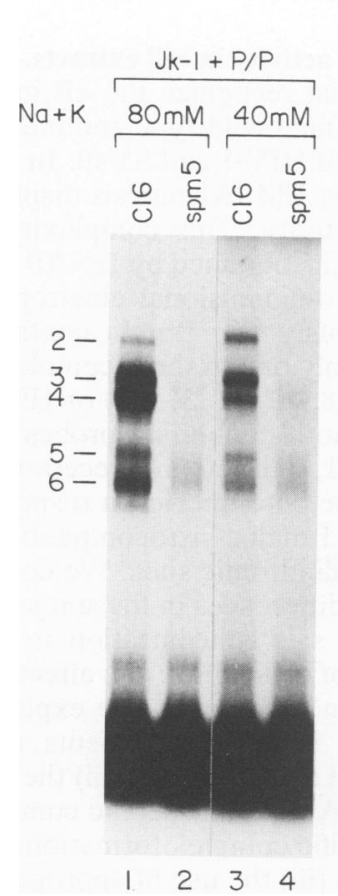

B

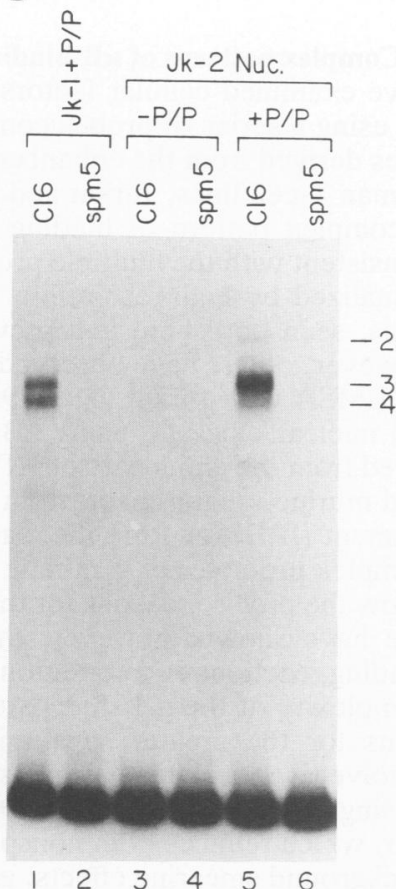

A

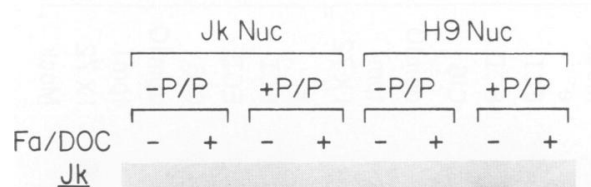

$\mathrm{B}$

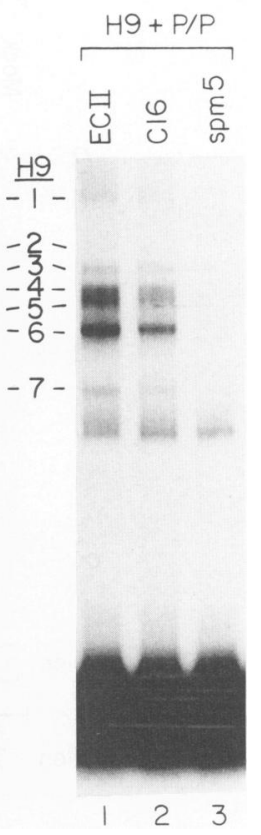

FIG. 5. Factors affecting the Jurkat EMSA pattern. (A) Jurkat nuclear extract binding activity at two concentrations of salt (total $\mathrm{NaCl}+\mathrm{KCl})(80 \mathrm{mM}$ [lanes 1 and 2] and $40 \mathrm{mM}$ [lanes 3 and 4] salt) with the wild-type $\mathrm{C} 16$ probe (lanes 1 and 3 ) or mutant spm5 probe (lanes 2 and 4). (B) Binding activity of nuclear extracts from different Jurkat cell cultures (Jk-1 versus Jk-2) is compared. Activity with the wild-type C16 probe (lanes 1,3 , and 5) and mutant spm5 probe (lanes 2, 4, and 6) is shown with extracts from PMA- and PHA-stimulated Jk-1 (lanes 1 and 2) and Jk-2 (lanes 5 and 6) cells and from unstimulated Jk-2 cells (lanes 3 and 4). A relatively short exposure is shown to illustrate the difference in formation of complexes $\mathrm{J} 3$ and $\mathrm{J} 4$ with two different extracts.

tion of the nuclear extract, or it may reflect a reassortment of $\mathrm{p} 50$ and $\mathrm{p} 65 \mathrm{NF}-\mathrm{kB}$ subunits that prior to denaturation were complexed with either themselves or with other proteins in the other complexes we observed.

Unlike the NF-kB-like complex, formation of the Jurkat cell complexes $\mathrm{J} 2$ and $\mathrm{J} 4$ and $\mathrm{H} 9$ cell complexes $\mathrm{H} 1, \mathrm{H} 2$, and H4 was disrupted by treatment with formamide and deoxycholate (Fig. 6A, compare lanes 3 and 4 and 5 and 8), whereas a new H9 complex, H3, was induced by the treatment. The remaining complexes were either unaffected (J5 and J6, compare lanes 3 and 4) or minimally reduced (H6 and $\mathrm{H} 7$, compare lanes 5 to 8 ). The decrease in formation of one or more of these complexes could result from the postulated reassortment of $\mathrm{p} 50$ and p65 subunits to generate the p50-p65 NF-kB-like complex, which is always enhanced by the formamide and deoxycholate treatment.

H9 cells display little PMA- and PHA-inducible $\mathrm{KB}$ motif enhancer activity. Because relatively high levels of transcriptional activity of multimerized $\mathbf{K B}$ enhancers have been observed in unstimulated $\mathrm{H} 9$ cells $(24,37)$, we did not expect to observe little or no NF- $\mathrm{kB}$ complex in nuclear extracts from these unstimulated $\mathrm{H} 9$ cells. Instead, in its place we observed a large number of $\mathrm{H} 9$ cell-specific $\mathrm{kB}$ motif complexes. This result suggests that one or more of the five evident unstimulated $\mathrm{H} 9$ cell-specific nuclear $\mathrm{KB}$ complexes

are responsible for the high levels of $\mathrm{kB}$-motif enhancer function in these cells. Given that, in Jurkat cell nuclear extracts, a large increase in several $\mathrm{KB}$ motif-binding activities correlates with a large increase in enhancer activity upon stimulation with PMA and PHA, we asked whether the activity of the multimerized $\mathrm{KB}$ motifs in $\mathrm{H} 9$ cells upon stimulation would also correlate with changes in total $\mathrm{kB}$ motif complex formation in these cells, in this case reflecting only the modest increases of several binding activities observed after stimulation.

We therefore tested the responses of the multimerized $\mathrm{kB}$ motif enhancers in $\mathrm{H} 9$ cells to stimulation with PMA and PHA as shown in Fig. 7. The reporter constructs have been described previously (37) and contain six tandem copies of individual wild-type or mutant sites inserted $2.2 \mathrm{~kb}$ downstream of the human $\beta$-globin gene transcriptional initiation site in the plasmid $\mathrm{pBe}^{-}$. The same plasmid with a single copy of the SV40 enhancer $(p \beta 1 \times 72)$ served as a positive control and as the reference for normalization. The $\mathrm{pBe} \mathrm{e}^{-}$ derivatives were transfected into $\mathrm{H} 9$ cells by electroporation along with an internal reference plasmid containing the human $\alpha$-globin gene. As with the preparation of the nuclear extracts, stimulated cells were treated for $8 \mathrm{~h}$ with PMA and PHA before being harvested at $24 \mathrm{~h}$ after electroporation. Cytoplasmic RNAs isolated from transfected cells were 

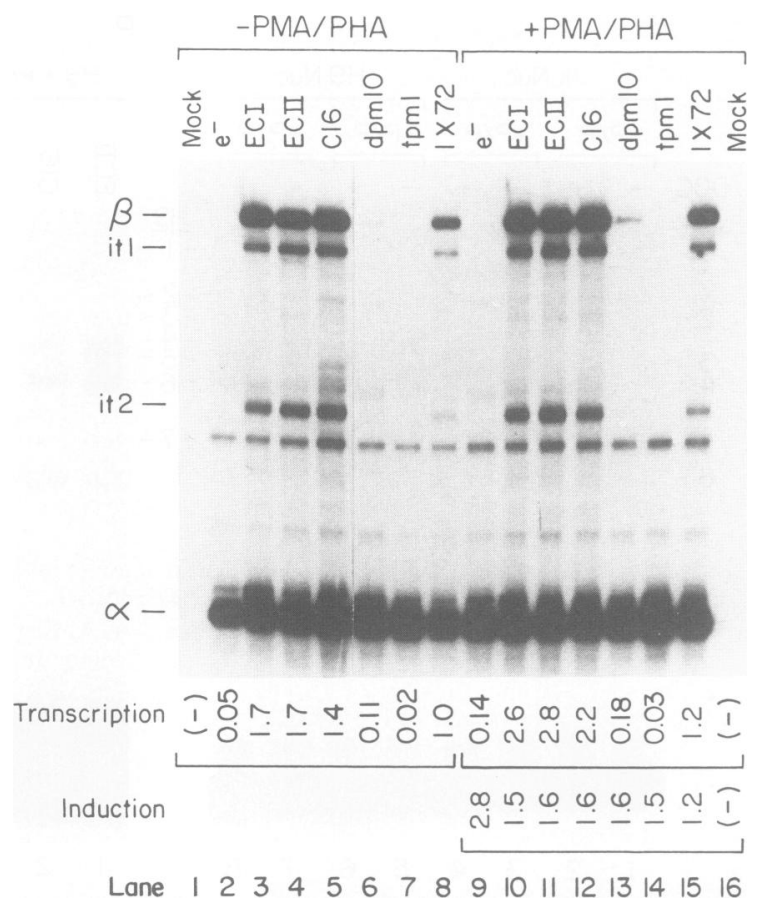

FIG. 7. Enhancer activity of multimerized $\kappa \mathrm{B}$ sites in $\mathrm{H} 9$ cells, as assayed by transient human $\beta$-globin gene expression, is weakly induced by treatment with PMA and PHA. The autoradiograph shows the levels of internal reference $\alpha$ - and experimental $\beta$-globin probe RNAs protected from RNase digestion by cytoplasmic RNA isolated from transfected cells. Transfection of the six-time series of $\beta$-globin reporter constructs indicated at the top of each lane was done as described in Materials and Methods. Protected fragments corresponding to correctly initiated $\alpha$-globin $(\alpha)$ and $\beta$-globin $(\beta)$ transcripts are indicated to the left; incorrectly processed $\beta$-globin readthrough transcripts are labeled it 1 and it 2 . Transcriptional activity, indicated beneath each lane, is expressed as the level of $\beta$-globin RNA normalized to the internal $\alpha$-globin reference, relative to the value for the SV40 enhancer $(p \beta 1 \times 72)$ control. Induced activity was normalized to uninduced $\mathrm{p} \beta 1 \times 72$ levels. The level of induction, indicated beneath lanes 9 to 16 , is the ratio of transcriptional activity between induced and uninduced cells.

probed for $\alpha$ - and $\beta$-globin transcripts by an RNase protection assay.

As shown in Fig. 7, the levels of $\beta$-globin transcript directed by the three wild-type $\kappa \mathrm{B}$ motifs in uninduced cells (lanes 3 to 5) were only slightly increased by stimulation of the transfected cells with PMA and PHA (lanes 10 to 12). The levels of $\beta$-globin transcript relative to those of the $1 \times 72$ SV40 enhancer and the fold induction (1.5- to 1.6-fold for the wild-type enhancers) are indicated at the bottom of the figure. The triple $\mathrm{\kappa B}$ motif point mutant tpm 1 did not display activity in either stimulated or unstimulated cells (lanes 7 and 14), whereas the double point mutant $d p m 10$ displayed similar low levels of activity in both cases (lanes 6 and 13); this latter result contrasts with the high activity of the $d p m 10$ mutant in stimulated Jurkat cells described previously (37). The high level of activity of the wild-type $\kappa B$ motif in unstimulated $\mathrm{H} 9$ cells and the small increase in activity upon stimulation of the cells with PMA and PHA correlate with the levels of the multiple $\mathrm{H} 9$ cell-specific $\kappa \mathrm{B}$ complexes, suggesting that the same $\mathrm{H} 9$ cell-specific complexes are active in both unstimulated and stimulated cells.

\section{DISCUSSION}

Complex patterns of $\kappa \mathrm{B}$-binding activity in cell extracts. We have examined cellular factors that recognize the $\mathrm{\kappa B}$ motif by using a series of probes containing wild-type and mutant sites derived from the enhancers of HIV-1 and SV40. In two human T-cell lines, Jurkat and H9, EMSA analysis displays a complex pattern of binding activity. This complexity is consistent with the multiple proteins obtained by DNAP and visualized by high-resolution, two-dimensional electrophoresis, seen both here and previously $(18,19)$. In contrast, however, others have observed only one to three complexes by EMSA with Jurkat $(4,8,19,28,29,32,33,47)$ or $\mathrm{H} 9$ (3, 19) nuclear extracts, using $\mathbf{k B}$ motif-containing probes derived from the enhancers of HIV-1, interleukin-2 receptor $\alpha$, and murine $\kappa$ light chain, from the beta interferon response element (IRE), or from the class I major histocompatibility complex promoter or synthetic palindromic sites. We do not know the precise reasons for the differences in these results. We have shown, however, that salt concentration in the binding reactions and conditions of cell culture can affect the complexity of the gel shift pattern. Other possible explanations for the greater sensitivity in our experiments may involve (i) the relatively large size of our probes; (ii) the use of single-stranded fish sperm DNA as a nonspecific competitor, which reduces both nonspecific complex formation and background smearing effects; and (iii) the use of appropriate glycerol/Ficoll ratios in the binding reaction, which inhibit band trailing effects, especially of the weaker, larger complexes.

With Jurkat cell nuclear extracts, at least six $\kappa \mathrm{B}$ motifspecific complexes were seen, all of which were greatly enhanced by stimulation with PMA and PHA. Although we have not established the identity of the proteins in these complexes, one of the complexes, J3, comigrated with the HeLa p50-p65 NF-kB heterodimer complex and was enhanced by mild treatment with denaturants. The two predominant complexes seen with nuclear extracts of Jurkat cells, $\mathrm{J} 3$ and $\mathrm{J} 4$, probably correspond to the two complexes $\mathrm{B} 1$ and $\mathrm{B} 2$ observed by Greene and coworkers $(8,32)$. Ultraviolet cross-linking studies showed the upper B1 complex to be composed of a mixture of four proteins with apparent mobilities of $50,55,75$, and $85 \mathrm{kDa}$ (p50, p55, p75, and p85, respectively); the lower B2 complex only contained the p50 and p55 proteins (32). p85 has been shown to be the product of c-rel, and p50 and p55 were shown to be similar to HeLa NF-kB p50 (7). Thus, the B2-J4 complex probably corresponds to a p50-p50 homodimeric DNA complex. It is possible that the B1-J3 complex (which we identified by EMSA as similar to p50-p65 NF-kB) is a mixture of at least two complexes that do not resolve in native gels, a p50-p75 NF- $\mathrm{kB}$ complex (where $75 \mathrm{kDa}$ is the apparent migration of p65 NF-kB) and a p50-p85 (c-Rel) complex.

Other laboratories have reported complex patterns of $\mathrm{kB}$ motif-binding activity in extracts of nonlymphoid cells lines, e.g., human cervical carcinoma $\mathrm{HeLa}$ cells (30) and murine $3 \mathrm{~T} 3$ fibroblasts (4), although not as complex as the Jurkat and $\mathrm{H} 9$ patterns described here. We have also observed a complicated EMSA pattern of $\mathbf{k B}$ motif complex formation with unstimulated HeLa cell nuclear extracts similar to the pattern observed with the Jurkat cell extracts and containing at least five $\kappa B$ motif-specific complexes (36). There are several possible candidates for proteins that may be involved in such generally expressed $\kappa \mathbf{B}$ motif-binding activities. One of the more slowly migrating complexes may correspond to the PRDII-BF1/MBP-1 factor, which is unique in that it does 
not contain a Rel homology domain but instead contains two zinc finger DNA-binding motifs $(5,17)$. Other factors in the complexes could be proteins shown by immunoprecipitation to associate with c-Rel (see reference 21 for a review) or the p49-p50B or RelB products of Rel-related cDNA clones identified recently $(9,41,43)$. The possibility that some of the more slowly migrating complexes are multimers of components bound in the faster-migrating complexes is unlikely because the relative levels of each complex do not vary over a 13-fold range of extract concentration in the binding assay (36). Although smaller complexes could contain degradation products of proteins in the larger complexes, this is unlikely because the gel shift pattern was reproducible with different extracts and a given extract was stable over long periods of time with repeated freezing and thawing (36).

H9 cells display a unique pattern of $\mathrm{\kappa B}$ motif-binding complexes. The unstimulated $\mathrm{H} 9$ cell nuclear extract EMSA pattern was as complex as that obtained from Jurkat cells, but the patterns obtained from these two human T-cell lines were completely different. Five complexes were obtained from extracts of unstimulated $\mathrm{H} 9$ cells, and two additional complexes, one comigrating with the p50-p65 NF-kB complex, were seen after stimulation with PMA and PHA. None of the complexes from uninduced $\mathrm{H} 9$ cells comigrated with any of the Jurkat cell complexes, with the exception of the NF- $\mathrm{BB}$-like $\mathrm{H} 5$ complex which appeared after mild denaturation of the extract (Fig. 6). The reason for the differences between the Jurkat and H9 cell EMSA patterns is not clear. Two possible explanations are cell line-specific modification of known $\mathrm{\kappa B}$ motif-binding gene products, e.g., by alternative splicing or posttranslational modification, or new cell type-specific gene products that have yet to be identified. Identification of new Rel-related gene products in $\mathrm{H} 9$ cells by cDNA cloning may serve to explain the observed differences in $\mathrm{\kappa B}$ complex formation with extracts from other cells.

Multiple non-NF-kB-binding complexes in $\mathbf{H 9}$ cells correlate with transcriptional enhancer activity. In both the $\mathrm{T}$-cell lines examined, nuclear extracts from cells with high $\mathbf{k B}$ transcriptional activity exhibited multiple binding activities. In the case of Jurkat cells, stimulation with PMA and PHA was required for elevation of transcriptional activity $(33,37,46)$. We have shown here that transcription elevation in Jurkat cells is accompanied by the induction of at least six binding complexes. On the other hand, in $\mathrm{H} 9$ cells transcriptional activity is already elevated in the absence of stimulation, in which five major $\mathbf{k B}$ motif-binding complexes are detectable, but no $N F-\kappa B$ is seen. The slight induction of enhancer activity by stimulation with PMA and PHA is accompanied by a slight induction of these five complexes and the appearance of a minor NF-kB complex. Thus, transcriptional activation by the $\kappa \mathrm{B}$ motif in $\mathrm{H} 9$ cells is likely mediated by one or more of the major non-NF-kB-binding complexes.

It is possible that in many cell types basal and inducible $\mathrm{kB}$ proto-enhancer activity is due to a group of $\mathbf{\kappa B}$ motif-specific binding proteins. The differences and complexities seen in the EMSA patterns generated by nuclear extracts from Jurkat and $\mathrm{H} 9$ cells, together with the identification of Rel-related $\kappa \mathbf{B}$ motif-binding proteins by cDNA cloning, suggest that like other families of transcription factors, e.g., the AP-1 transcription complex (see reference 13 for a review), a family of proteins may be involved in eliciting transcriptional activation by the $\mathbf{\kappa B}$ proto-enhancer.

\section{ACKNOWLEDGMENTS}

We thank Nouria Hernandez, Jacek Skowronski, and Kanna Visvanathan for comments on the manuscript; J. Reader for help in preparation of the manuscript; and J. Duffy and P. Renna for artwork. The QUEST laboratory at Cold Spring Harbor Laboratory performed the two-dimensional gel electrophoresis.

These studies were funded by grants AI27270 and AI31825 (NIAID) to W.H. and by grant AI27270 (NIAID) and a grant from the Mellam Family Trust to B.R.F.

\section{REFERENCES}

1. Baeuerle, P. A. 1991 . The inducible transcription activator NF-kB: regulation by distinct protein subunits. Biochim. Biophys. Acta 1072:63-80.

2. Baeuerle, P. A., and D. Baltimore. 1988. Activation of DNAbinding activity in an apparently cytoplasmic precursor of the NF-kB transcription factor. Cell 53:211-217.

3. Baeuerle, P. A., and D. Baltimore. 1988. IkB: a specific inhibitor of the NF- $\mathrm{KB}$ transcription factor. Science 242:540-546.

4. Baldwin, A. S., Jr., J. C. Azizkhan, D. E. Jensen, A. A. Beg, and L. Coodly. 1991. Induction of NF-kB DNA-binding activity during the $G_{0}$-to- $G_{1}$ transition in mouse fibroblasts. Mol. Cell. Biol. 11:4943-4951.

5. Baldwin, A. S., Jr., K. P. LeClair, H. Singh, and P. A. Sharp. 1990. A large protein containing zinc finger domains binds to related sequence elements in the enhancers of the class I major histocompatibility complex and kappa immunoglobulin genes. Mol. Cell. Biol. 10:1406-1414.

6. Ballard, D. W., E. Böhnlein, J. A. Hoffman, H. P. Bogerd, E. P. Dixon, B. R. Franza, and W. C. Greene. 1989. Activation of the interleukin-2 receptor $\alpha$ gene: regulatory role for DNA-protein interactions flanking the $\mathrm{\kappa B}$ enhancer. New Biol. 1:83-92.

7. Ballard, D. W., W. H. Walker, S. Doerre, P. Sista, J. A. Molitor, E. P. Dixon, N. J. Peffer, M. Hannink, and W. C. Greene. 1990. The v-rel oncogene encodes a $\mathrm{kB}$ enhancer binding protein that inhibits NF-KB function. Cell 63:803-814.

8. Böhnlein, E., J. W. Lowenthal, M. Siekevitz, D. W. Ballard, B. R. Franza, and W. C. Greene. 1988. The same inducible nuclear protein regulates mitogen activation of both the interleukin-2 receptor-alpha gene and type 1 HIV. Cell 53:827-836.

9. Bours, V., P. R. Burd, K. Brown, J. Villalobos, S. Park, R.-P. Ryseck, R. Bravo, K. Kelly, and U. Siebenlist. 1992. A novel mitogen-inducible gene product related to $\mathrm{p} 50 / \mathrm{p} 105-\mathrm{NF}-\mathrm{kB}$ participates in transactivation through a $\mathbf{~} \mathbf{B}$ site. Mol. Cell. Biol. 12:685-695.

10. Bours, V., J. Villalobos, P. R. Burd, K. Kelly, and U. Siebenlist. 1990. Cloning of a mitogen-inducible gene encoding a $\mathrm{kB}$ DNA-binding protein with homology to the rel oncogene and to cell-cycle motifs. Nature (London) 348:76-80.

11. Bradford, M. M. 1976. A rapid and sensitive method for the quantitation of microgram quantities of protein utilizing the principle of protein-dye binding. Anal. Biochem. 72:248-254.

12. Brownell, E., N. Mittereder, and N. R. Rice. 1989. A human rel proto-oncogene cDNA containing an $A$ lu fragment as a potential coding exon. Oncogene 4:935-942.

13. Curran, T., and B. R. Franza, Jr. 1988. Fos and Jun: the AP-1 connection. Cell 55:395-397.

14. Davis, N., S. Ghosh, D. L. Simmons, P. Tempst, H.-C. Liou, D. Baltimore, and H. R. Bose, Jr. 1991. Rel-associated pp40: an inhibitor of the Rel family of transcription factors. Science 253:1268-1271.

15. Dignam, J. D., R. M. Lebowitz, and R. G. Roeder. 1983. Accurate transcription initiation by RNA polymerase II in a soluble extract from isolated mammalian nuclei. Nucleic Acids Res. 11:1475-1489.

16. Dynan, W. S. 1989. Modularity in promoters and enhancers. Cell 58:1-4.

17. Fan, C.-M., and T. Maniatis. 1990. A DNA-binding protein containing two widely separated zinc finger motifs that recognize the same DNA sequence. Genes Dev. 4:29-42.

18. Franza, B. R., Jr. 1990. Complex protein interactions at the human immunodeficiency virus, type 1 (HIV-1) direct repeat enhancer structure: a paradigm for database analysis of protein- 
nucleic acid interactions, p. 181-189. In J. E. Groopman I. S. Y. Chen, M. Essex, and R. A. Weiss (ed.), Human retroviruses. Wiley-Liss, New York.

19. Franza, B. R., Jr., S. F. Josephs, M. Z. Gilman, W. Ryan, and B. Clarkson. 1987. Characterization of cellular proteins recognizing the HIV enhancer using a microscale DNA-affinity precipitation assay. Nature (London) 330:391-395.

20. Ghosh, S., A. M. Gifford, L. R. Riviere, P. Tempst, G. P. Nolan, and D. Baltimore. 1990. Cloning of the p50 DNA binding subunit of NF-kB: homology to rel and dorsal. Cell 62:1019-1029.

21. Gilmore, T. D. 1990 . NF-kB, kBF1, dorsal, and related matters. Cell 62:841-843.

22. Herr, W., and Y. Gluzman. 1985. Duplications of a mutated simian virus 40 enhancer restore its activity. Nature (London) 313:711-714.

23. Kanno, M., C. Fromental, A. Staub, F. Ruffenach, I. Davidson, and P. Chambon. 1989. The SV40 TC-II $(\kappa B)$ and the related $H-2 K^{B}$ enhansons exhibit different cell type specific and inducible proto-enhancer activities, but the SV40 core sequence and the AP-2 binding site have no enhanson properties. EMBO J. 8:4205-4214.

24. Kaufman, J. D., G. Valandra, G. Rodriquez, G. Bushar, C. Giri, and M. A. Norcross. 1987. Phorbol ester enhances human immunodeficiency virus-promoted gene expression and acts on a repeated 10-base-pair functional enhancer element. Mol. Cell. Biol. 7:3759-3766.

25. Kieran, M., V. Blank, F. Logeat, J. Vandekerckhove, F. Lottspeich, O. Le Bail, M. B. Urban, P. Kourilsky, P. A. Baeuerle, and A. Israel. 1990. The DNA binding subunit of NF-kB is identical to factor $\mathrm{kBF} 1$ and homologous to the rel oncogene product. Cell 62:1007-1018.

26. Lee, J. H., Y. Li, S. Doerre, P. Sista, D. W. Ballard, W. C. Greene, and B. R. Franza, Jr. 1991. A member of the set of $\mathbf{k B}$ binding proteins, HIVEN86A, is a product of the human c-rel proto-oncogene. Oncogene 6:665-667.

27. Lenardo, M. J., and D. Baltimore. 1989. NF-kB: a pleiotropic mediator of inducible and tissue-specific gene control. Cell 58:227-229.

28. Lenardo, M. J., C.-M. Fan, T. Maniatis, and D. Baltimore. 1989. The involvement of $\mathrm{NF}-\mathrm{kB}$ in $\beta$-interferon gene regulation reveals its role as widely inducible mediator of signal transduction. Cell 57:287-294.

29. Leung, K., and G. J. Nabel. 1988. HTLV-1 transactivator induces interleukin-2 receptor expression through an NF-kBlike factor. Nature (London) 333:776-778.

30. Macchi, M., J.-M. Bornert, I. Davidson, M. Kanno, R. Rosales, M. Vigneron, J.-H. Xiao, C. Fromental, and P. Chambon. 1989. The SV40 TC-II $(\mathrm{kB})$ enhanson binds ubiquitous and cell type specifically inducible nuclear proteins from lymphoid and nonlymphoid cell lines. EMBO J. 8:4215-4227.

31. Meyer, R., E. N. Hatada, H.-P. Hohmann, M. Haiker, C. Bartsch, U. Röthlisberger, H.-W. Lahm, E. J. Schlaeger, A. P. G. M. van Loon, and C. Scheidereit. 1991. Cloning of the DNA-binding subunit of human nuclear factor $\kappa B$ : the level of its mRNA is strongly regulated by phorbol ester or tumor necrosis factor $\alpha$. Proc. Natl. Acad. Sci. USA 88:966-970.

32. Molitor, J. A., W. H. Walker, S. Doerre, D. W. Ballard, and W. C. Greene. 1990 . NF-кB: a family of inducible and differentially expressed enhancer-binding proteins in human $\mathrm{T}$ cells. Proc. Natl. Acad. Sci. USA 87:10028-10032.
33. Nabel, G., and D. Baltimore. 1987. An inducible transcription factor activates expression of human immunodeficiency virus in T cells. Nature (London) 326:711-713.

34. Nolan, G. P., S. Ghosh, H.-C. Liou, P. Tempst, and D. Baltimore. 1991. DNA binding and IKB inhibition of the cloned p65 subunit of NF-кB, a rel-related polypeptide. Cell 64:961-969.

35. Ondek, B., A. Shepard, and W. Herr. 1987. Discrete elements within the SV40 enhancer region display different cell-specific enhancer activities. EMBO J. 6:1017-1025.

36. Phares, W., B. R. Franza, and W. Herr. Unpublished results.

37. Phares, W., and W. Herr. 1991. Functional similarities between human immunodeficiency virus type 1 and simian virus $40 \mathrm{kB}$ proto-enhancers. J. Virol. 65:2200-2210.

38. Pierce, J. W., M. Lenardo, and D. Baltimore. 1988. Oligonucleotide that binds nuclear factor NF-kB acts as a lymphoidspecific and inducible enhancer element. Proc. Natl. Acad. Sci. USA 85:1482-1486.

39. Popovic, M., M. G. Sarngadharan, E. Read, and R. C. Gallo. 1984. Detection, isolation, and continuous production of cytopathic retroviruses (HTLV-III) from patients with AIDS and pre-AIDS. Science 224:497-500.

40. Ruben, S. M., P. J. Dillon, R. Schreck, T. Henkel, C.-H. Chen, M. Maher, P. A. Baeuerle, and C. A. Rosen. 1991. Isolation of a rel-related human cDNA that potentially encodes the $65-\mathrm{kD}$ subunit of NF-kB. Science 251:1490-1493.

41. Ryseck, R.-P., P. Bull, M. Takamiya, V. Bours, U. Siebenlist, P. Dobrzanski, and R. Bravo. 1992. RelB, a new Rel family transcription activator that can interact with p50-NF-kB. Mol. Cell. Biol. 12:674-684.

42. Schirm, S., J. Jiricny, and W. Schafiner. 1987. The SV40 enhancer can be dissected into multiple segments, each with a different cell type specificity. Genes Dev. 1:65-74.

43. Schmid, R. M., N. D. Perkins, C. S. Duckett, P. C. Andrews, and G. J. Nabel. 1991. Cloning of an NF-kB subunit which stimulates HIV transcription in synergy with p65. Nature (London) 352:733-736.

44. Sen, R., and D. Baltimore. 1986. Multiple nuclear factors interact with the immunoglobulin enhancer sequences. Cell 46:705-716.

45. Sen, R., and D. Baltimore. 1986 . Inducibility of $\kappa$ immunoglobulin enhancer-binding protein NF- $\mathrm{kB}$ by a posttranslational mechanism. Cell 47:921-928.

46. Tong-Starksen, S. E., P. A. Luciw, and M. Peterlin. 1987. Human immunodeficiency virus long terminal repeat responds to T-cell activation signals. Proc. Natl. Acad. Sci. USA 84: $6845-6849$.

47. Urban, M. B., and P. A. Baeuerle. 1990 . The $65-\mathrm{kD}$ subunit of $\mathrm{NF}-\mathrm{KB}$ is a receptor for $I_{\kappa} B$ and a modulator of DNA-binding specificity. Genes Dev. 4:1975-1984.

48. Urban, M. B., R. Schreck, and P. A. Baeuerle. 1991. NF-kB contacts DNA by a heterodimer of the p50 and p65 subunit. EMBO J. 10:1817-1825.

49. Weiss, A., R. L. Wiskocil, and J. D. Stobo. 1984. The role of T3 surface molecules in the activation of human $T$ cells: a twostimulus requirement for Il 2 production reflects events occurring at a pre-translational level. J. Immunol. 133:123-128.

50. Wilhelmsen, K. C., K. Eggleton, and H. M. Temin. 1984. Nucleic acid sequences of the oncogene v-rel in reticuloendotheliosis virus strain $\mathrm{T}$ and its cellular homolog, the protooncogene c-rel. J. Virology 52:172-182. 